A computational approach thermoelectric power generators to estimate heat flux

\author{
Avijit Nayak ${ }^{1}$, RK Nayak ${ }^{2}$ \\ ${ }^{1}$ Assistant Prof. Department of Mechanical Engineering, \\ Gandhi Institute of Technology \& Management, \\ 752054 Saraswati Vihar, Gangapada Bhubaneswar, Odisha,India. \\ *Email:avijitnayak@gmail.com \\ ${ }^{2}$ Department of Mechanical Engineering, College of Engineering, \\ Patia, Bhubaneswar, Odisha, India
}

\begin{abstract}
This paper focuses on establishing the limiting value of input heat flux for thermoelectric generators (TEG) under different environmental and operating conditions. The current study investigates the limiting input heat flux for TEG's with allowable hot side temperature of $150^{\circ} \mathrm{C}$.A fin block with 8 fin configuration and fin length of $60 \mathrm{~mm}$ is chosen as heat sink configuration for TEG. Computational Fluid Dynamics (CFD) model is developed and analyzed in this work after validation with published experimental results. CFD model consists of 4 TEGs encapsulated within a target block and a finned block, placed within a low speed wind tunnel. Forced laminar air flow in the wind tunnel up to $14 \mathrm{~m} / \mathrm{s}$ simulates the outdoor wind conditions. Concentrated solar flux is applied to the face of the target block. Effect of ambient air temperature, fin material is studied. Angle of Attack (AOA) and wind direction which arises due to the 2 axis tacking of sun by Fresnel lens concentrator has also been studied and it is observed that maximum heat flux reaches $24,850 \mathrm{~W} / \mathrm{m}^{2}$ for the TEG at $14 \mathrm{~m} / \mathrm{s}$ wind speed, $24,000 \mathrm{~W} / \mathrm{m}^{2}$ for $30^{\circ}$ Angle of Attack (AOA) under $5 \mathrm{~m} / \mathrm{s}$ wind velocity. It is also observed that maximum heat flux varies by $147.77 \%$ with a change in wind velocity from 0 to $5 \mathrm{~m} / \mathrm{s}$, while the change is $11.43 \%$ when the change from 5 to $14 \mathrm{~m} / \mathrm{s}$.
\end{abstract}

Keywords: Angle of attack; Finned heat sink; Solar flux; Thermoelectric generator (TEG); Wind direction; Wind tunnel.

\title{
INTRODUCTION
}

Thermoelectric generators (TEG) work on the principle of Seebeck effect converting thermal energy directly into electricity. An open circuit electric voltage is generated in the TEG when there is a temperature difference between the two sides (hot and cold sides) of the TEG. The higher temperature difference can be created between the two sides by applying larger heat flux on the hot side and providing effective means of heat dissipation on the colder side. Commercial TEGs are made up of semiconductors where series connected p-n junction couples are sandwiched between ceramic plates. The maximum operating temperature of a TEG is defined with respect to the materials used in it. The advantage of TEG's is that it can 
convert low grade thermal energy directly into electricity and secondly, since TEG's have no moving parts it is nearly maintenance free over its operating life. The limiting value of input heat flux would change for a TEG depending upon the type of heat sink and cooling method implemented.

There are a number of articles were published before, some most related articles were listed below, the author have explained the Peltier effect considering it as a non-isothermal effect. They have predicted the barrier-less thermoelectric effect which generally occurs together with Peltier effect [1]. The author have developed a detail balanced model on Solar Thermoelectric generators (STEG), which incorporates concentrated solar flux with TEGs for power generation. The model uses a thermoelectric compatibility theory to provide an analytical solution for device efficiency. They have shown a STEG having a hot side temperature of $1000{ }^{\circ} \mathrm{C}$ under $100 \mathrm{kWm}^{-2}$ incident solar fluxes could achieve an efficiency of $15.9 \%$. Similarly, the efficiency can rise to $30.9 \%$ for a STEG with hot side temperature $1500^{\circ} \mathrm{C}[2]$. Authors have proposed a discrete numerical model for the evaluation of STEG. STEG system design and selection of cooling methods have been provided [3]. The authors have provided a two-stage optimization process for heat sink design for performance enhancement of TEGs [4]. Authors have discussed the possibility of combining TEGs with traditional open fire stoves for electricity generation and running of an electric fan for increasing air to fuel ratio for complete combustion in the stoves, thus improving stove efficiency [5,6]. The authors have presented a review on nanostructure composites for thermoelectric applications as they exhibit nanostructures and properties that improve thermoelectric figure of merit [7]. The authors focus on principles of thermoelectric power production, performance and materials used as well as its application areas [8]. The authors have presented design and test results of a combined thermo-siphon and thermoelectric modules for generation of electricity from salinity-gradient solar pond acting as heat source [9]. The authors provided theoretical analysis and experimental investigation on TEGs installed on the copper receiver plate positioned at the focal point of a parabolic dish solar collector [10]. The authors had provided a theoretical model for the determination of the limit of solar concentration for TEGs under passive cooling conditions. Further expanded their work to include two commercially available TEGs were chosen for experimentation. Both outdoor and indoor experimentation was conducted for different configuration of the heat sink. Indoor setup of the experiment consisted of a low-speed wind tunnel, within which the TEGs were placed sandwiched between the target block and finned block. The heat source was provided by electric heating elements [11]. The authors numerically investigated the effect of a positive angle of attack on the convective heat transfer coefficient [12]. The authors provided an analytical solution for heat and mass transfer for fluids flowing across an isothermal flat plate and new relation were developed [13]. The authors studied to determine the average heat transfer coefficients for forced convection of air over a rectangular flat pate through experimentation and numerical approach. Experimental results were correlated within an accuracy of $+/-12 \%$ [14].

See beck effect, the working principle of TEG has been extensively explained by many researchers. Nanostructure composites have been investigated as a material for TEG applications. Numerical and experimental studies have been carried out by varying the sources of heat (low grade thermal) for TEG. Different methods of concentration of solar flux were applied as a heat source for TEGs. Different heat sinks designs for TEG heat dissipation were investigated. Both active and passive regimen of airflow for heat dissipation 
has been investigated. While two axis tracking has been proposed for TEGs with concentrated solar heat flux (parabolic dish and Fresnel lens concentrators) and effect of wind flow over finned block heat sink has been studied, but both the parameters in conjugation has not been investigated. Keeping the wind direction fixed, due to solar tracking, finned block makes different tilt angle (Angle Of Attack) with respect to the wind direction. The angle of attack has an effect on the heat transfer coefficient for a flat plate as demonstrated by the authors $[15,16]$.

There are many researchers carried out research work both experimentally and numerically to estimate heat flux for Thermo Electric Generator. In this present scientific research paper limiting input heat flux for Thermoelectric generator under concentrated solar flux has been established through computational fluid dynamics approach and effect of angle of attack of the fin block on the limiting heat flux has been studied. Therefore, the angle of attack of the finned block to the wind direction would affect the limiting input heat flux for the TEG. The effect of the tilt angle on the limiting value of heat flux has been investigated in this paper. Although the direction of wind has been kept fixed (normal to face) while investigating the effect of AOA on the TEG, in reality the wind direction relative to fin face can attain any value depending upon the factors affecting the orientation of the test assembly like the latitude of the test location, two-axis tracking of sun and local factors affecting the wind direction. Thus the effect of wind direction on the limiting input heat flux for TEGs too has been investigated. Also, the year-round operation of TEG would involve seasonal variation in ambient air temperature; therefore the effect of ambient air temperature on the limiting input heat flux for TEGs has also been studied. In this scientific research paper, the effect of wind direction flowing over the fin block on the limiting heat flux has been studied and the material aspect of the fin block on limiting heat flux has also been found out.

\section{MATHEMATICAL MODELLING}

\section{Setup and Computational Model}

In the present investigation, 4 TEGs (each $40 \mathrm{~mm} \times 40 \mathrm{~mm}$ and $3 \mathrm{~mm}$ thick) having total power generation capacity of $1.6 \mathrm{~W}(0.4 \times 4)$ under a flux of $20,000 \mathrm{~W} / \mathrm{m}^{2}$ [12], are placed in contact in $2 \times 2$ configuration within an $80 \mathrm{~mm} \times 80 \mathrm{~mm}$ and $2 \mathrm{~mm}$ deep machined slot on a $100 \mathrm{~mm} \times 100 \mathrm{~mm}$ and $20 \mathrm{~mm}$ thick aluminum block which is used as target or spreader. Another aluminum block (base plate) of $100 \mathrm{~mm} \times 100 \mathrm{~mm}$ and $20 \mathrm{~mm}$ thick is placed over the TEGs upon which 8 rectangular plate fins are attached each having a thickness of $1 \mathrm{~mm}$ and length and height as $80 \mathrm{~mm}$ and $60 \mathrm{~mm}$ respectively. The fin spacing is kept at $10 \mathrm{~mm}$. The base block along with fins acts as a heat sink for the TEG rejecting heat to the ambient air flowing over it. Details of the TEG test assembly are presented in fig. 1(inset). The optimization of a number of fins and fin spacing has been presented by authors [11], therefore the present study doesn't focus on those aspects. The assembly is placed within a horizontally oriented square duct of dimension $400 \mathrm{~mm}$ x $400 \mathrm{~mm}$ and having a length of $1000 \mathrm{~mm}$ which acts a low-speed wind tunnel simulating the flow of wind over the fins. Figure. 1 shows the TEG assembly within the wind tunnel. Figure. 2 shows the difference in orientation of the test assembly at $0^{\circ} \mathrm{AOA}$ and $45^{\circ}$ AOA. Figure. 3 shows Schematic representation of the difference in orientation of test assembly to wind direction. (X-Z plane, $Y=45 \mathrm{~mm}$ ). 


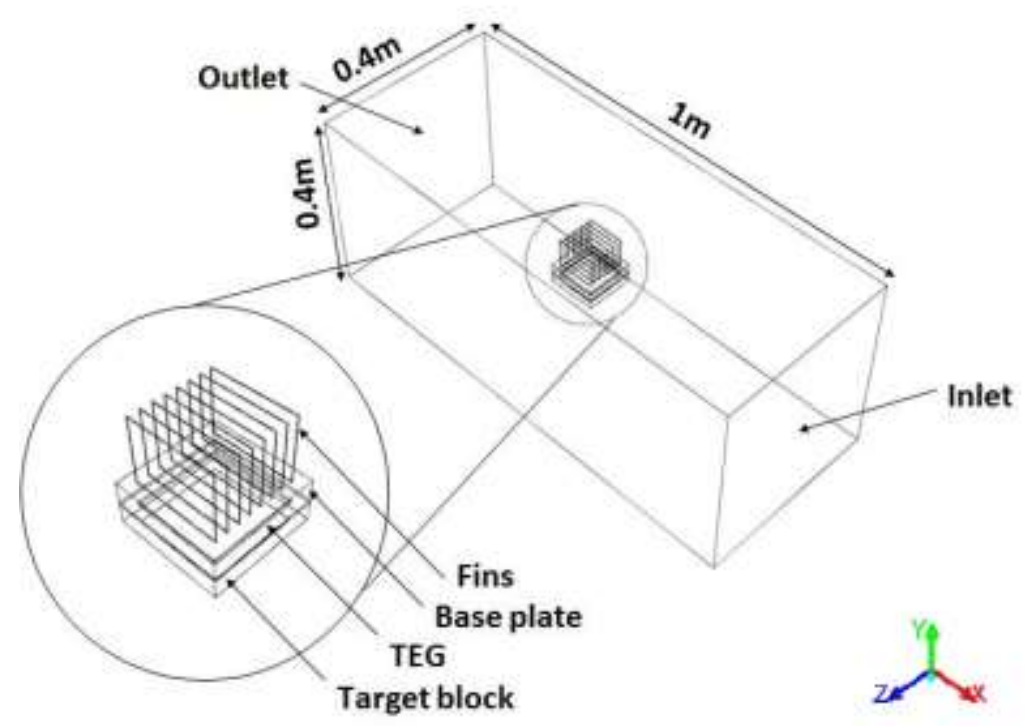

Figure 1.Schematic layout of the TEG test assembly placed within the low-speed wind tunnel.
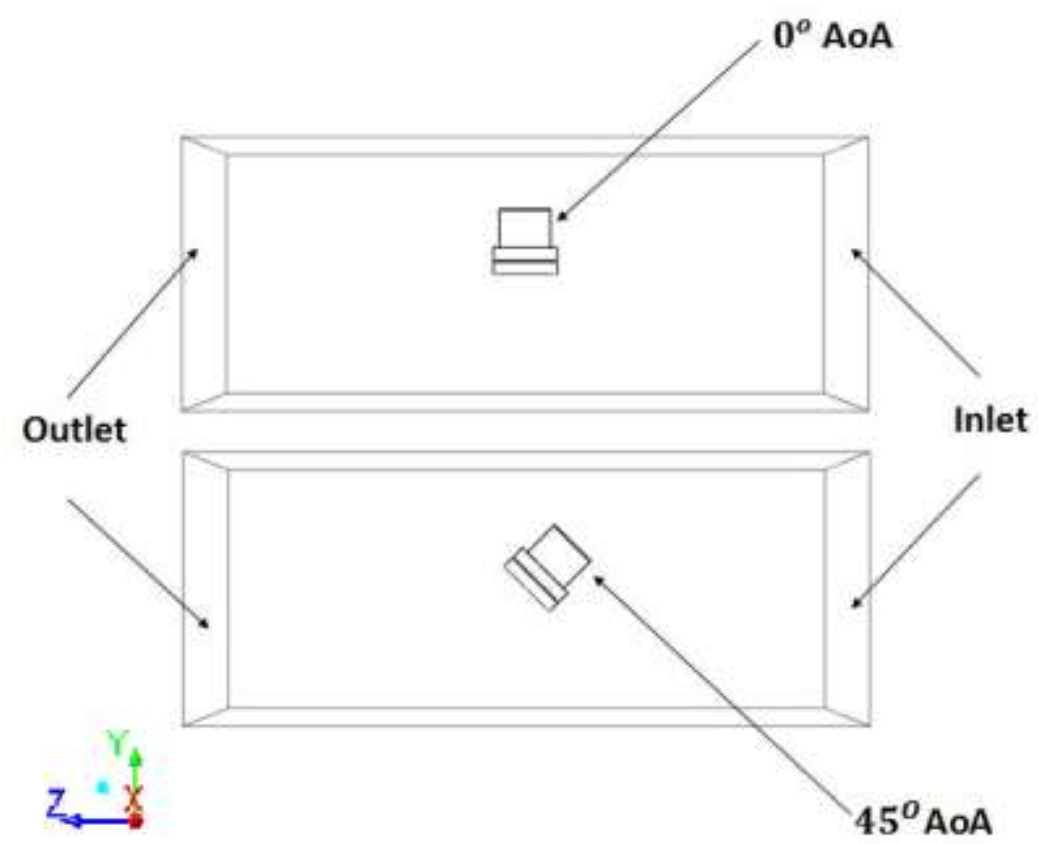

Figure 2.Schematic representation of the difference in orientation of test assembly for different AOA. 


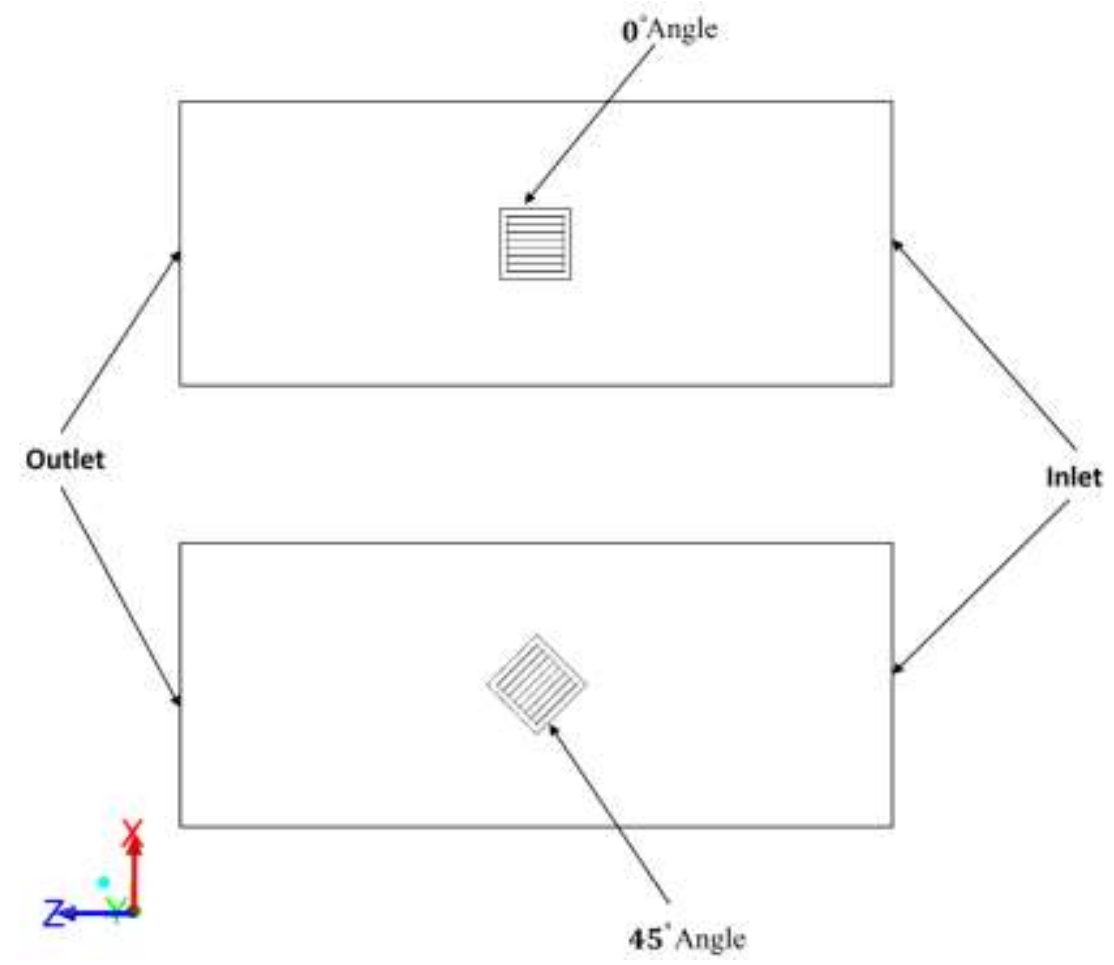

Figure 3.Schematic representation of the difference in orientation of test assembly to wind direction. $(\mathrm{X}-\mathrm{Z}$ plane, $\mathrm{Y}=45 \mathrm{~mm})$

\section{Meshing}

Since the computational domain consists of multi-body part, having both solid and fluid bodies therefore hybrid meshing has been chosen wherein solid and fluid bodies have meshed separately. Advanced size function has been used for mesh refinement. Particularly proximity and curvature have been chosen to refine the mesh in the contact region of two surfaces, thus a non-uniform grid is generated. This is particularly helpful in capturing the heat transfer from the fin surface to ambient air. Refinement is also required due to the presence of inclined surfaces. A number of cells are controlled by relevance tool, which is particularly helpful in suppressing numerical diffusion arising due to an excessive number of cells.

\section{Mathematical Formulations}

Conservation equations for mass, momentum, and energy are solved iteratively with the appropriate boundary condition, which is mentioned below.

Continuity equation

$$
\frac{\partial u}{\partial x}+\frac{\partial v}{\partial y}+\frac{\partial w}{\partial z}=0
$$

Momentum equation

X-momentum

$$
u \frac{\partial u}{\partial x}+v \frac{\partial u}{\partial y}+w \frac{\partial w}{\partial z}=-\frac{1}{\rho} \frac{\partial p}{\partial x}+v\left(\frac{\partial^{2} u}{\partial x^{2}}+\frac{\partial^{2} u}{\partial y^{2}}+\frac{\partial^{2} u}{\partial z^{2}}\right)
$$


Y-momentum

$$
u \frac{\partial v}{\partial x}+v \frac{\partial v}{\partial y}+w \frac{\partial v}{\partial z}=-\frac{1}{\rho} \frac{\partial p}{\partial x}+v\left(\frac{\partial^{2} v}{\partial x^{2}}+\frac{\partial^{2} v}{\partial y^{2}}+\frac{\partial^{2} v}{\partial z^{2}}\right)
$$

Z-momentum

$$
u \frac{\partial u}{\partial x}+v \frac{\partial w}{\partial y}+w \frac{\partial w}{\partial z}=-\frac{1}{\rho} \frac{\partial p}{\partial z}+v\left(\frac{\partial^{2} w}{\partial x^{2}}+\frac{\partial^{2} w}{\partial y^{2}}+\frac{\partial^{2} w}{\partial z^{2}}\right)
$$

Energy Equation

$$
u \frac{\partial T}{\partial x}+v \frac{\partial T}{\partial y}+w \frac{\partial T}{\partial z}=\alpha\left(\frac{\partial^{2} T}{\partial x^{2}}+\frac{\partial^{2} T}{\partial y^{2}}+\frac{\partial^{2} T}{\partial z^{2}}\right)
$$

Commercial software ANSYS $®$ Fluent $®$ (ANSYS FLUENT. User's guide) is employed for the iterative procedure to solve the above equations. Steady pressure based solver has been employed. Spatial discretization is carried out using a second-order upwind scheme for convective terms in momentum and energy equations. Pressure has been discretized with a standard scheme. SIMPLE (Semi-Implicit Method for Pressure-Linked Equations) algorithm has been used for pressure-velocity coupling. SIMPLE being a segregated algorithm, the pressure is updated at the end of the iteration. The energy equation is solved using the laminar model. Default values of under-relaxation factors have been kept throughout the simulations. The convergence criterion for all the equations is set to $10^{-6}$.

\section{Assumptions}

1. Flow is steady, laminar and single phase.

2. Air is treated as Newtonian and incompressible. Thermo-Physical properties are assumed constant (temperature independent).

3. No slip boundary conditions were used on the walls of the wind tunnel and walls of the test assembly.

4. Thermal radiation heat transfer being small has been neglected.

5. Heat transfer gel has not been modeled as a CFD model ensures perfect contact of surfaces.

6. Concentrated heat flux through Fresnel lens on the target/ spreader block of TEG has been considered. Diffuse solar radiation has been neglected.

\section{Boundary Conditions}

Following boundary conditions have been used. Velocity inlet boundary condition is used at the inlet of the wind tunnel denoted as $\mathrm{V}_{\text {in }}$, specified normal to be a boundary. Velocity inlet boundary condition is well suited as the simulation replicates the prevalent ambient condition of flow over the finned block. The temperature at the inlet is $T_{i n}$, which is equal to $T_{\text {inf, }}$ which is the ambient wind temperature. At the outlet pressure, outlet boundary condition has been specified with zero gauge pressure (atmospheric pressure). The wind tunnel walls are kept adiabatic so that there is no thermal interaction between the test assembly and the walls of 
the wind tunnel so that wall temperature does not affect the solution. In the bottom surface of the target or spreader block, the flux boundary condition is employed. The value of flux employed is equivalent to concentrated solar flux through the Fresnel lens. The TEG bottom and top surface temperature are noted and flux is increased or decreased to keep the TEG bottom surface temperature within $150+/-1{ }^{\circ} \mathrm{C}$.

\section{Material Properties}

Lists the materials and fluid with their properties are listed in Table 1(a) and Table 1(b). [11),P.Holman Heat and mass transfer.

Table 1(a). List of material properties.

\begin{tabular}{|c|c|c|c|c|}
\hline Materials & & $\rho\left(\mathrm{Kg} / \mathrm{m}^{3}\right)$ & $C_{p}(\mathrm{j} / \mathrm{Kg}-\mathrm{K})$ & $k(\mathrm{~W} / \mathrm{m}-\mathrm{K})$ \\
\hline Aluminum (Al) & & 2719 & 871 & 180 \\
\hline Copper (Cu) & & 8978 & 381 & 387.6 \\
\hline $\begin{array}{l}\text { Bismuth } \\
\left(\mathrm{Bi}_{2} \mathrm{Te}_{3}\right)\end{array}$ & Telluride & 7850 & 200 & 1.1 \\
\hline
\end{tabular}

Table 1(b). List of fluid property.

\begin{tabular}{lllll}
\hline Fluid & $C_{p}(\mathrm{j} / \mathrm{Kg}-\mathrm{K})$ & $k(\mathrm{~W} / \mathrm{m}-\mathrm{K})$ & $\mu(\mathrm{Kg} / \mathrm{m}-\mathrm{s})$ & $\dot{m}(\mathrm{Kg} / \mathrm{Kgmol})$ \\
\hline Air & 1006.43 & 0.0242 & 0.000017894 & 28.996 \\
\hline
\end{tabular}

\section{RESULT AND DISCUSSION}

\section{Grid independence study}

A grid independence study has been conducted using different grid sizes. The grid is progressively refined from 204,034 to 501,989 by increasing the number of elements. A grid with 444,382 elements is selected for further study as the TEG bottom surface temperature lies within $150+/-1^{\circ} \mathrm{C}$. Grid independence study is carried out for aluminum fins at $0^{\circ}$ angle of attack and $5 \mathrm{~m} / \mathrm{s}$ wind velocity with ambient temperature $16^{\circ} \mathrm{C}$ and input flux used is $22,200 \mathrm{~W} / \mathrm{m}^{2}$ which is the theoretical limiting value of heat flux for the above mentioned condition as presented in [11]. Figure. 4 present the finding of the grid independence test. The TEG bottom surface temperature obtained is plotted against the number of elements in the grid used for that simulation. 


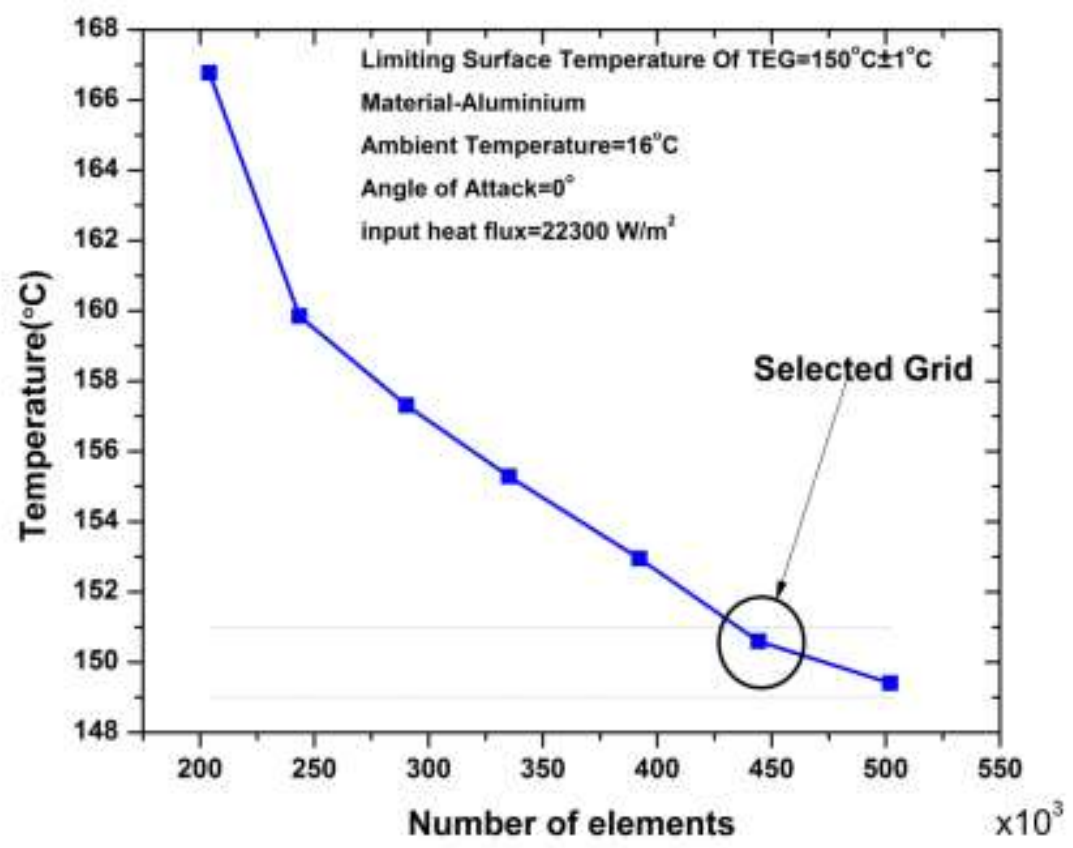

Figure 4.Variation of TEG hot surface temperature with a number of elements in the grid.

\section{Model Validation}

Validation of current numerical methodology has been carried out with the experimental and theoretical results of the indoor wind tunnel experiment presented in reported paper [11]. The geometrical parameters in the numerical method have been kept similar to the experiment alone [15]. The source of flux in experimentation being electric resistance heater has been changed to flux boundary condition. The comparative results of experimental [11], theoretical [15], and numerical values of limiting input heat flux for 8 fins $60 \mathrm{~mm}$ aluminum heat sink under $0 \mathrm{~m} / \mathrm{s}$ to $5 \mathrm{~m} / \mathrm{s}$ wind speed and $16^{\circ} \mathrm{C}$ ambient air temperature has been presented in fig. 5 . It is seen that theoretical value of limiting input heat flux for $5 \mathrm{~m} / \mathrm{s}$ is 22,200 $\mathrm{W} / \mathrm{m}^{2}$ and the experimental value being $21,400 \mathrm{~W} / \mathrm{m}^{2}$ while corresponding numerical method value obtained was $22,300 \mathrm{~W} / \mathrm{m}^{2}$. Similarly, for natural convection case theoretical and experimental values are $10,700 \mathrm{~W} / \mathrm{m}^{2}$ and $8,100 \mathrm{~W} / \mathrm{m}^{2}$ respectively. While numerical method value is $9,000 \mathrm{~W} / \mathrm{m}^{2}$. Hence it is concluded that numerical results are in good agreement with the theoretical and experimental data. The validated model has been used for parametric studies. The entire simulation regime is carried out by changing one parameter and keeping other parameters constant. By statically uncertainty Analysis the value of relative error between the stimulated results and experimental is less than $9 \%$. 


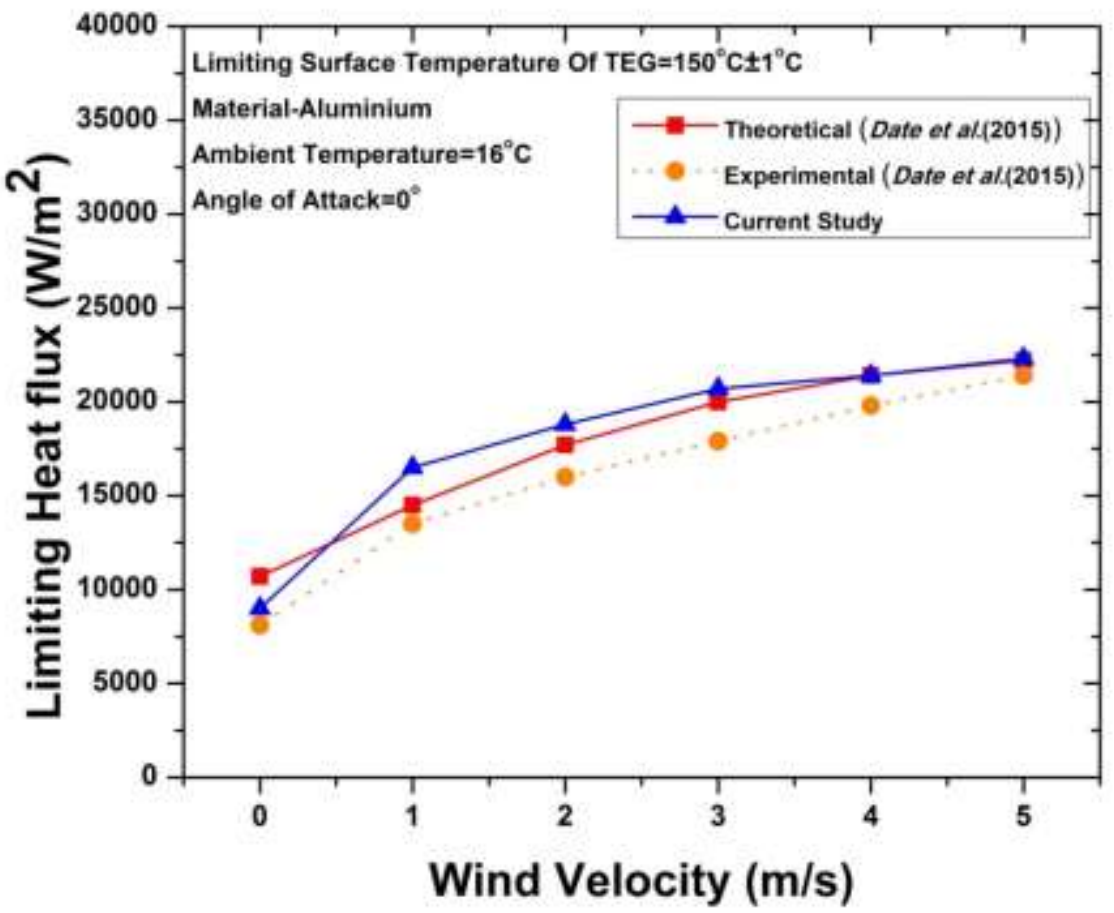

Figure 5. Limiting input heat flux variation with wind velocity for the current study and comparison with experimental and theoretical values.

\section{Effect of wind velocity}

Fig. 6shows the variations of limiting input heat flux with wind velocity. The authors in their study have presented the relationship between the aforementioned parameters; they had restricted their study in the passive cooling region which is up to $5 \mathrm{~m} / \mathrm{s}$ [11]. In this present work, wind speed has been increased up to $14 \mathrm{~m} / \mathrm{s}$ to check the increase in the limiting input flux in the forced laminar region, which is presented in fig. 6 . It is seen that maximum heat flux varies by $147.77 \%$ with a change in wind velocity from 0 to $5 \mathrm{~m} / \mathrm{s}$, while the change is $11.43 \%$ when the wind velocity increases from 5 to $14 \mathrm{~m} / \mathrm{s}$. This is due to the reason that the relationship between the increases in heat transfer coefficient to the increase in wind speed is not linear. The rate of rising in the value of heat transfer coefficient due to an increase in wind velocity decreases as the wind velocity increases. This coupled with the fact that the temperature gradient between the fin surface and the ambient air decreases with the increase in wind velocity for the fact that fin surface temperature $T_{S}$ decreases with an increase in wind velocity. These two parameters in combination decrease the rate of rising of limiting input heat flux with an increase in wind velocity, which can be clearly seen from the figure. 6. Therefore the small increase in the input heat flux would not justify the additional auxiliary power requirement for running a fan or blower to create the higher wind speed. 


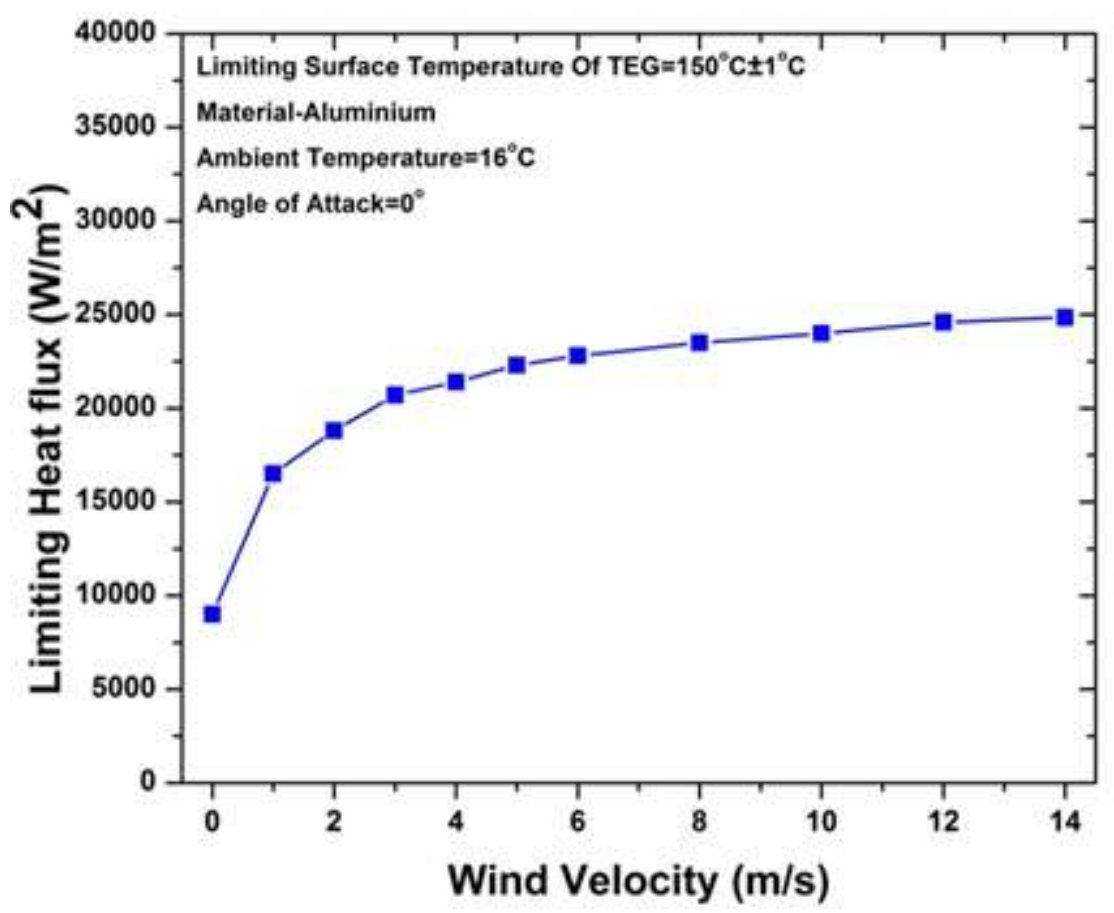

Figure 6. Variation of limiting input heat flux with wind velocity ranging from $0-14 \mathrm{~m} / \mathrm{s}$.

\section{Effects of Aluminium and Copper as Fin Materials}

A comparative analysis has been performed by changing the material of the fin (material of the target block and base plate have been changed as well). Two materials have been investigated, aluminum and copper having thermal conductivity $180 \mathrm{~W} / \mathrm{m}^{2} \mathrm{~K}$ and $401 \mathrm{~W} / \mathrm{m}^{2} \mathrm{~K}$ respectively. As seen from the figure. 7 there is no advantage offered by copper with its higher thermal conductivity. Since the temperature is limited to $150^{\circ} \mathrm{C}$ in the entire domain, aluminum (melting point $660.3^{\circ} \mathrm{C}$ ) is preferred over copper fins (from an economic standpoint). 


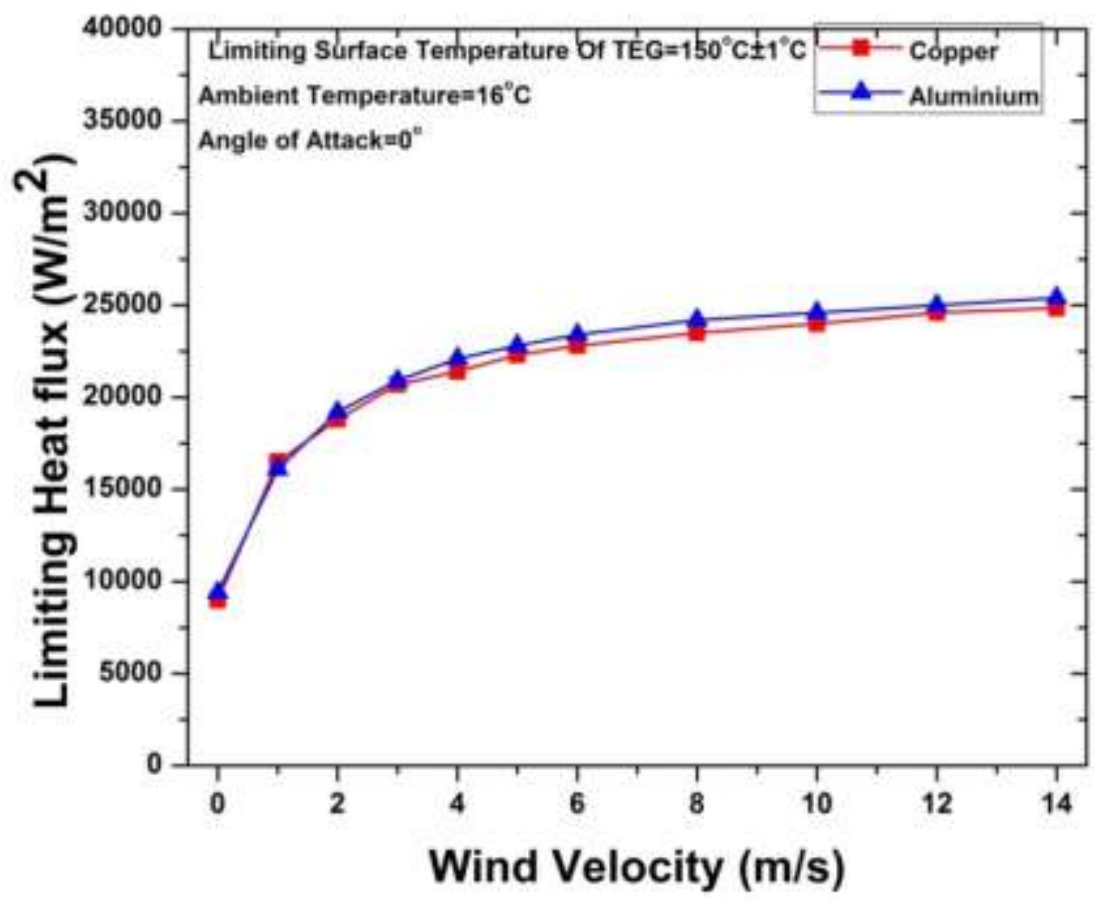

Figure 7.The comparative graph for variation of limiting input heat flux with wind velocity for Aluminium and Copper fin blocks.

\section{Effect of Ambient Temperature}

With the year-round operation, TEG would encounter a change in ambient temperature due to seasonal variation. Figure. 8presents the variation in the limiting input heat flux for different ambient air temperatures $\left(10^{\circ} \mathrm{C}\right.$ to $\left.35^{\circ} \mathrm{C}\right)$. Three values $(2 \mathrm{~m} / \mathrm{s}, 5 \mathrm{~m} / \mathrm{s}, 8 \mathrm{~m} / \mathrm{s})$ of wind speed have been investigated. As stated earlier in section 3.3the forced laminar active region $(8 \mathrm{~m} / \mathrm{s})$ offers less advantage over the passive region $(0 \mathrm{~m} / \mathrm{s}$ to $5 \mathrm{~m} / \mathrm{s})$, and it holds true for all values ambient air temperatures investigated. This is again due to the combined effect of a decrease in the rate of rising in heat transfer co-efficient with wind velocity and a decrease in surface temperature of the fins as discussed in section 3.3. 


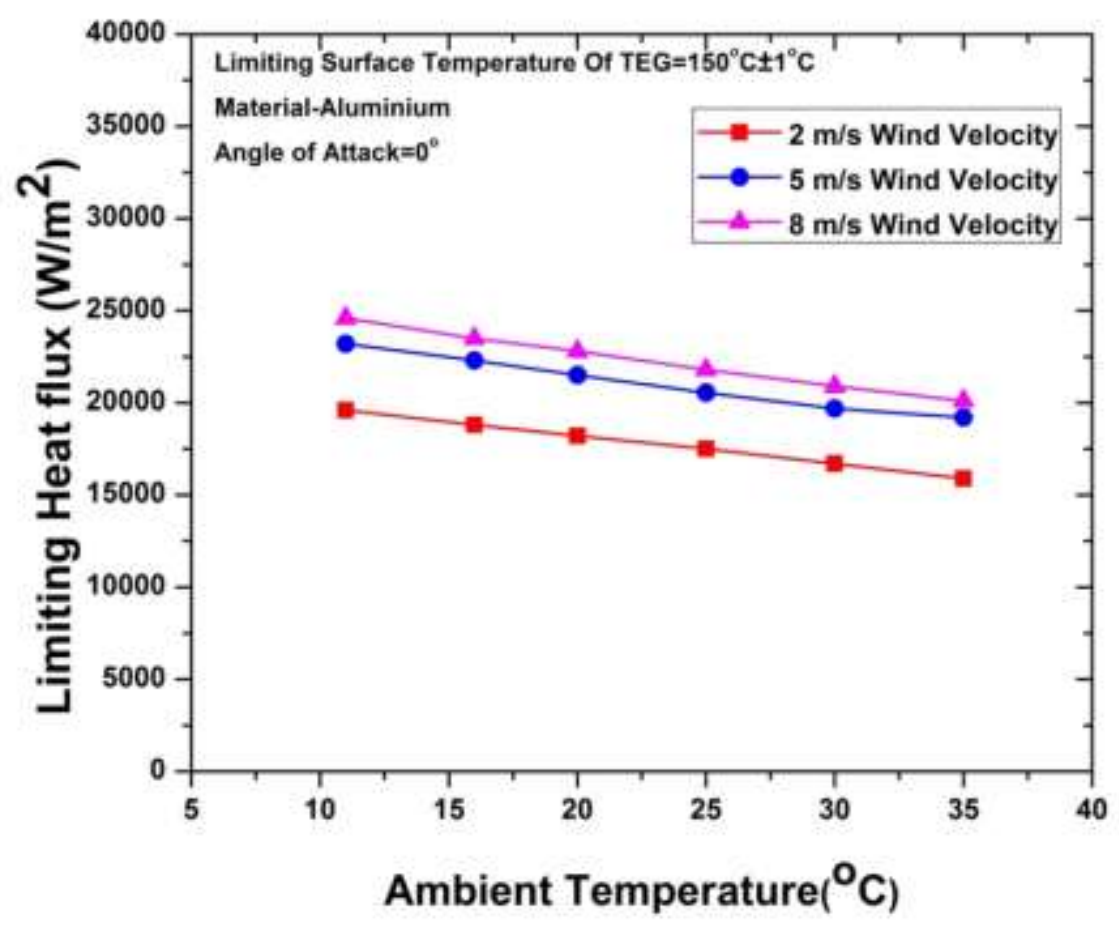

Figure 8. Variation of limiting input heat flux with ambient temperature.

\section{Effect of Angle of Attack (AOA)}

Day-long operation of TEG under concentrated solar flux would require 2 axis tracking of the sun (Parabolic dish system or Fresnel lens concentrators). This tracking would create a different angle (Angle of attack) (In Y-Z plane)of the finned block heat sink of TEG with the wind direction [17-20]. This angle would have an effect on the limiting input heat flux for the TEG. Therefore the effect of AOA has been studied keeping wind direction constant and tilting the test assembly (for angles $15^{\circ}, 30^{\circ}, 45^{\circ}, 60^{\circ}$, and $75^{\circ}$ ). $90^{\circ}$ tilt has not being considered as it would represent sun position at the horizon, where there is not enough Direct Normal Irradiation (DNI) for meaningful flux concentration leading to power generation. Fig. 9 depicts the comparative analysis of the effect of AOA on the Nusselt number ratio.

$$
N u=\frac{h l^{*}}{k}
$$

$l^{*}=$ Effective length

Nuratio $=\frac{\mathrm{Nu}(\mathrm{X})}{\mathrm{Nu}\left(30^{\circ}\right)}(7)$

$\mathrm{X}=0^{\circ}, 15^{\circ}, 30^{\circ}, 45^{\circ}, 60^{\circ}, 75^{\circ}$

Comparative result analysis has been done for finned heat sink block with flat plate CFD analysis and experimentation and analytical approach by authors [12-14]. It shows that finned block heat sink has a similar behavior to a flat plate under a different angle of attack. The values of limiting input heat flux vary by $5.41 \%$ between $30^{\circ}$ to $75^{\circ} \mathrm{AOA}$. Figure. 10represents the graph between Nusselt number ratio and angle of attack for different wind 
velocities. As it can be seen the wind velocity has minimal effect on the Nusselt number ratio for all angle of attack. Figure.11 represents the graph between the limiting input heat flux and the ambient wind velocity for different AOA. As it can be seen the limiting input heat flux has a maximum value at $30^{\circ} \mathrm{AOA}$ for all wind velocities closely followed by $45^{\circ} \mathrm{AOA}$. Limiting input heat flux is $24000 \mathrm{~W} / \mathrm{m}^{2}$ for $5 \mathrm{~m} / \mathrm{s}$ wind velocity $30^{\circ} \mathrm{AOA}$ and $22300 \mathrm{~W} / \mathrm{m}^{2}$ for $5 \mathrm{~m} / \mathrm{s}$ and $0^{\circ} \mathrm{AOA}$. Thus a change of $7.62 \%$ is observed in limiting input heat flux due to the variation of tilt angle with the incoming wind direction.

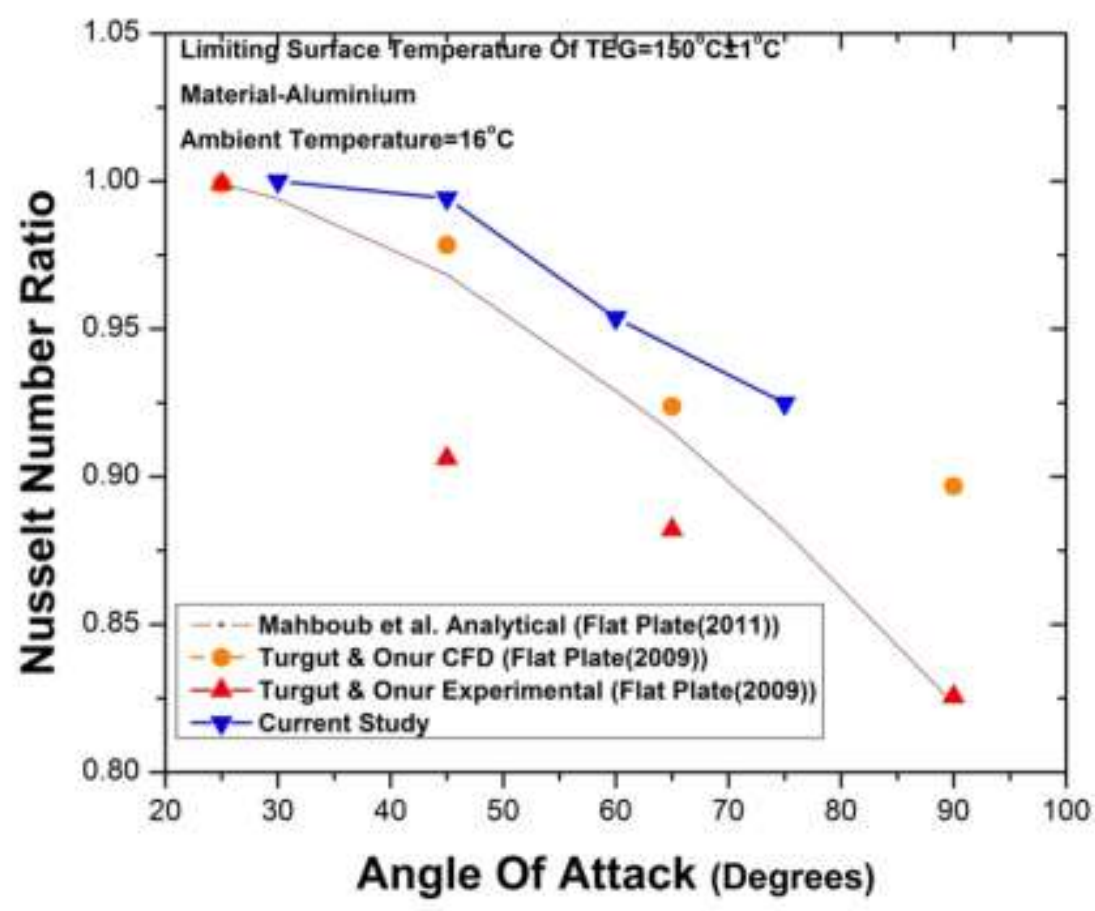

Figure 9. Variation of Nusselt number ratio with AOA for the present study, comparison with CFD and Experimentation. 


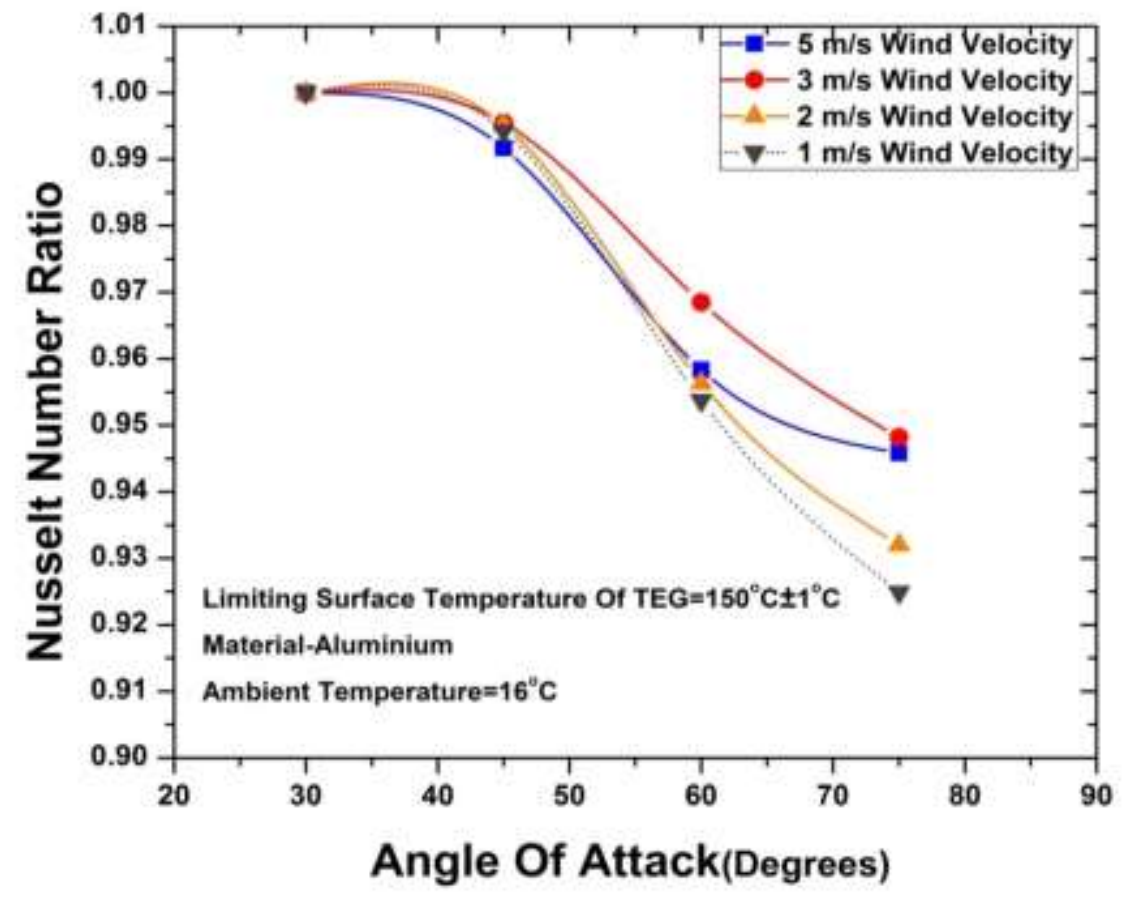

Figure 10.Variation of Nusselt number ratio with AOA for different wind velocities.

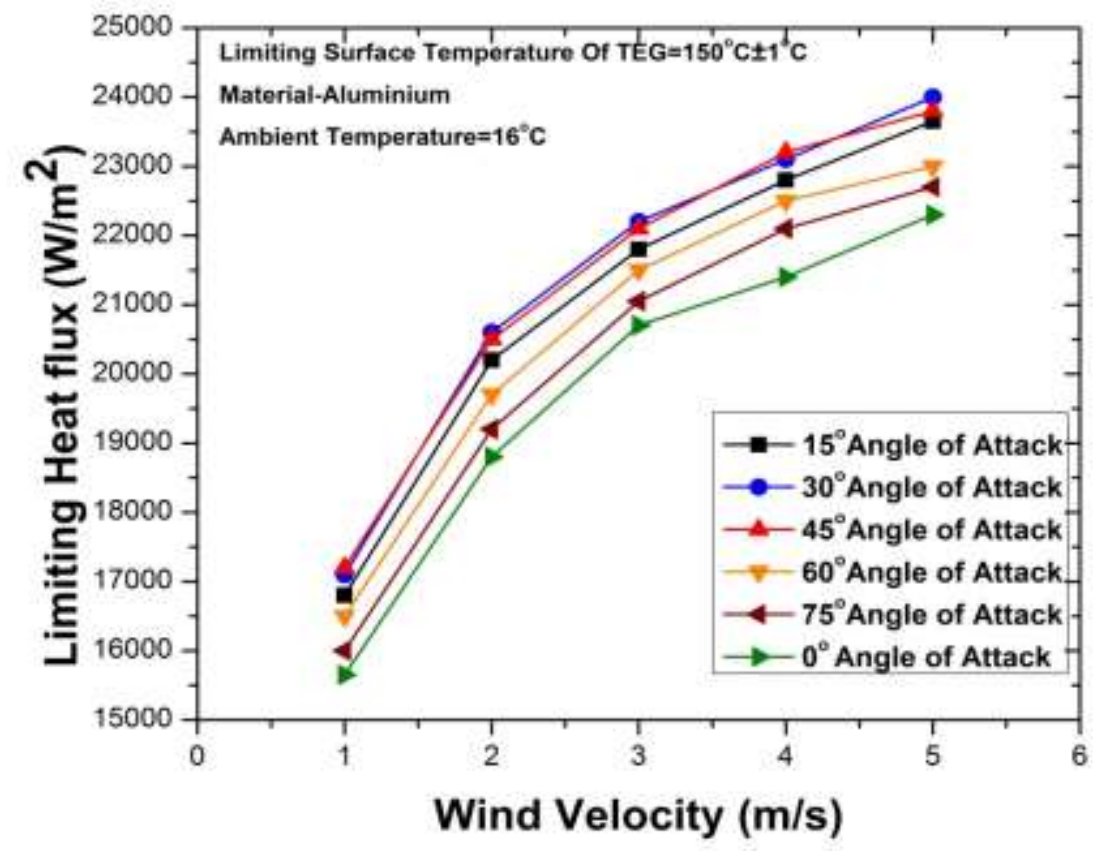

Figure 11. Variation of limiting input heat flux with wind velocity for different AOA. 
Figure. 11 shows the TEG assembly temperature contour for different AOA.As it can be seen the region of higher temperature distribution in the domain is nearly equivalent to the spread (area) of the wake region. Limiting input heat flux increases from $0^{\circ} \mathrm{AOA}$ to $30^{\circ} \mathrm{AOA}$ then reduces from $45^{\circ}$ to $75^{\circ} \mathrm{AOA}$. This phenomenon can be attributed to two factors, increased in heat transfer length (diagonal length) and decrease in velocity (decrease in heat transfer coefficient) within the finned block. Due to the interaction of the two factors, the highest heat transfer is reported at $30^{\circ} \mathrm{AOA}$.Figure. 13 compares the velocity and pressure contours of the domain for different AOA. Figure. 14 compares the velocity vectors (expanded cutaway) for different AOA. The total test assembly behaves like a bluff body placed in a flow field. The orientation (AOA) determines the position of the leading edge and the separation of flow. The spread (area) of the wake too is AOA dependent (degree of bluffness). Within the test assembly, the spreader block, TEG, and target block behave as a bluff body but the finned block although offers resistance to the flow, due to its thickness being small (1 mm) does not behave as a bluff body. As seen in the figure. 13 (a) the stagnation point is located at the face of the base block and the separation occurs at the bottom edge of the spreader block. But as the test assembly is tilted, the position of the stagnation point is shifted gradually to the edge of the base plate block and beyond to the top face of the base plate top, where the fins are attached as seen in the figure. 13 (b) to (f). The portion of the finned block exposed to the high-pressure region also increases with increase in the AOA as seen from figure.14 (a) to (f) The increase in the region of high pressure and shifting of the stagnation point directly translates to the decrease in velocity of wind within the fin gaps reducing the heat transfer rate and consequently the limiting input heat flux as seen in figure. 11. Also with higher AOA the leading edge where separation takes place is shifted from the bottom edge of the spreader block to the top edge of the base plate block as clearly seen from the figure. 14 (a) to (f). This inhibits the heat transfer from the base plate block face and the spreader block face with increases in AOA as early separation takes place. This phenomenon too translates into less heat transfer with an increase in AOA. The above factors do not explain the reason for the increase in heat transfer and consequently increase in limiting input heat flux from $0^{\circ} \mathrm{AOA}$ to $30^{\circ}$ AOA where peak limiting input heat flux is observed. The rise can be explained by the fact that angular entry of the wind into the finned block breaks the thick boundary layer formed in the region of the fin root (fin attachment to the base plate) and base plate top as seen when comparing figure. 14 (a) and (c). This is true for $0^{\circ}$ to $30^{\circ} \mathrm{AOA}$. But as the AOA increases from $45^{\circ}$ to $75^{\circ}$ the stagnation point figure 13(d) to (f)is shifted to the top face of base plate block hindering the wind flow in that region. This is evident in figure 14 (d) to (f), which represents the velocity vector. The heat transfer in the region of the base of the fin and top face of the base plate is important as maximum temperature gradient is obtained there as fin base and un-finned (gap region) of the base plate has the highest temperature as shown in the figure. 15. Due to the angular entry of the wind, if the thick boundary layer is broken and heat transfer is enhanced, it will get reflected as a decrease in fin root/base temperature as shown in the figure. 16 where fin temperature is minimum for AOA $30^{\circ}$ and maximum for $75^{\circ} \mathrm{AOA}$. 


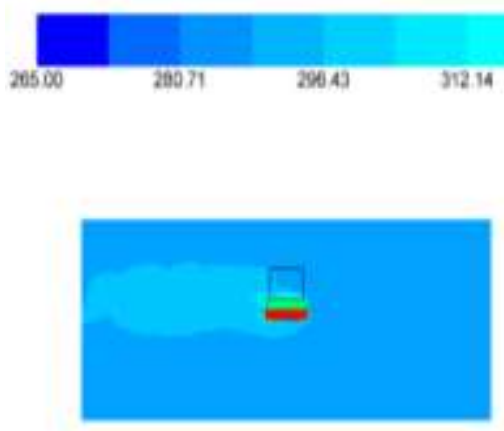

(a)

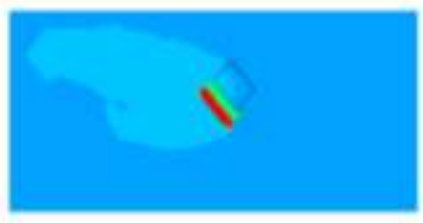

(d)

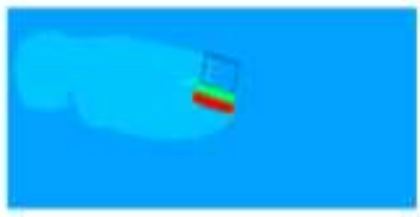

(b)

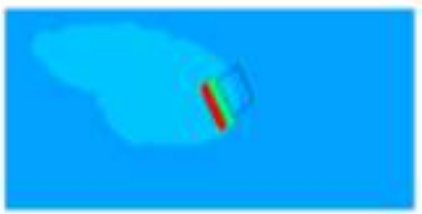

(e)

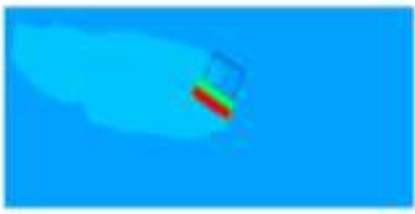

(c)

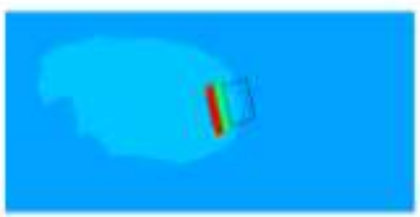

(f)

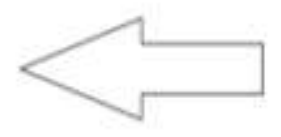

Wind Direction

Figure 12.The contour of temperature in the domain for (a) $0^{\circ}$ (b) $15^{\circ}$ (C) $30^{\circ}$ (d) $45^{\circ}$ (e) $60^{\circ}$ (f) $75^{\circ} \mathrm{AOA}$. 


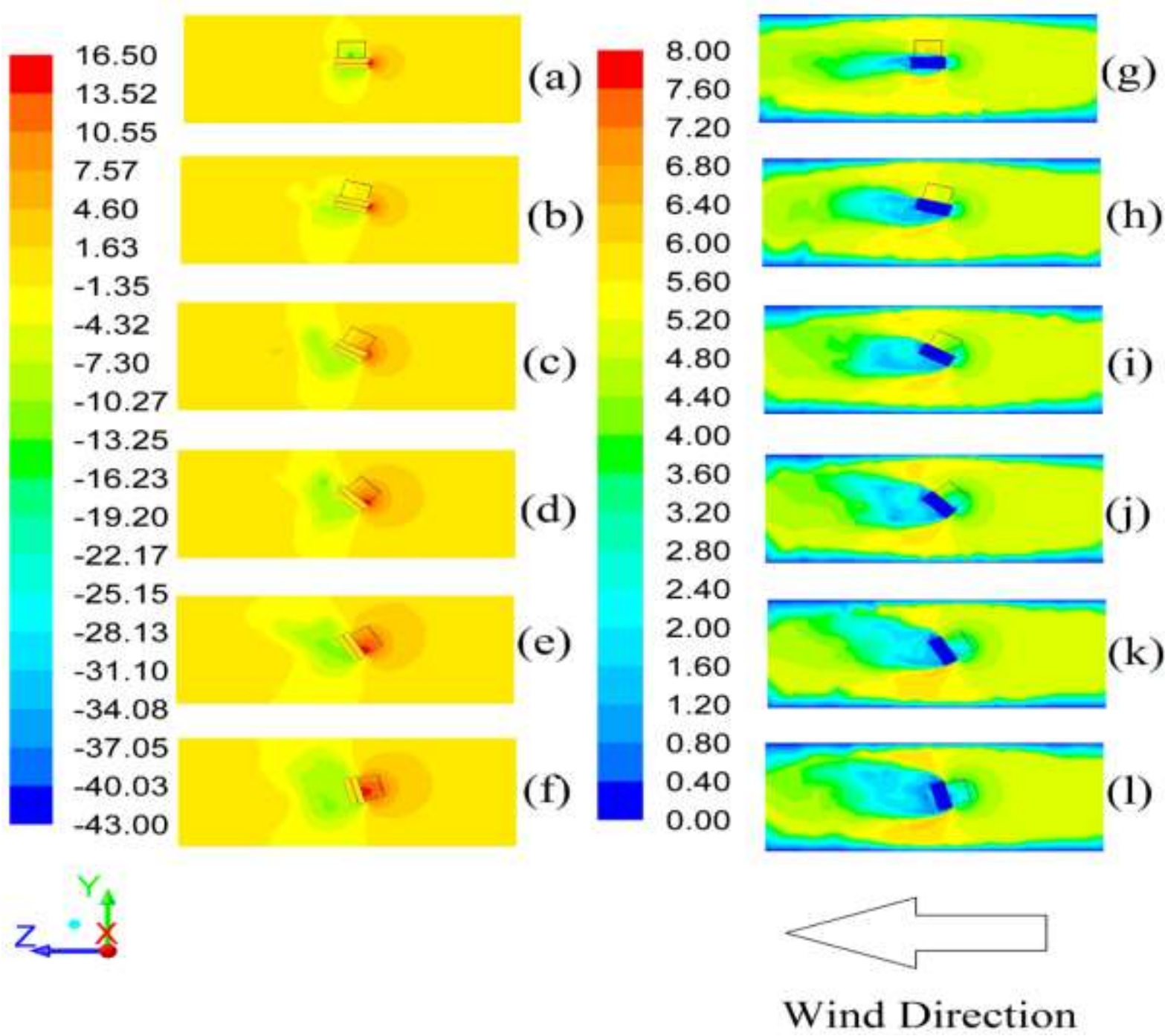

Figure 13. Contours of pressure and velocity in the domain, pressure contours (a) $0^{\circ}$ (b) $15^{\circ}$ (C) $30^{\circ}$ (d) $45^{\circ}$ (e) $60^{\circ}$ (f) $75^{\circ} \mathrm{AOA}$ and velocity contours (g) $0^{\circ}$ (h) $15^{\circ}$ (i) $30^{\circ}$ (j) $45^{\circ}$ (k) $60^{\circ}$ (1) $75^{\circ} \mathrm{AOA}$. 


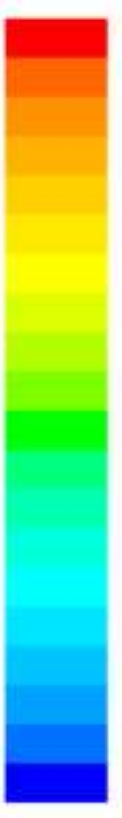
9.00
8.55
7.65
7.20
6.75
6.30
5.85
5.40
4.95
4.50
4.05
3.60
3.15
2.70
2.25
1.80
1.35
0.90
0.45
0.00

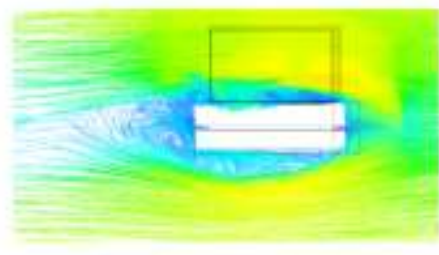

(a)
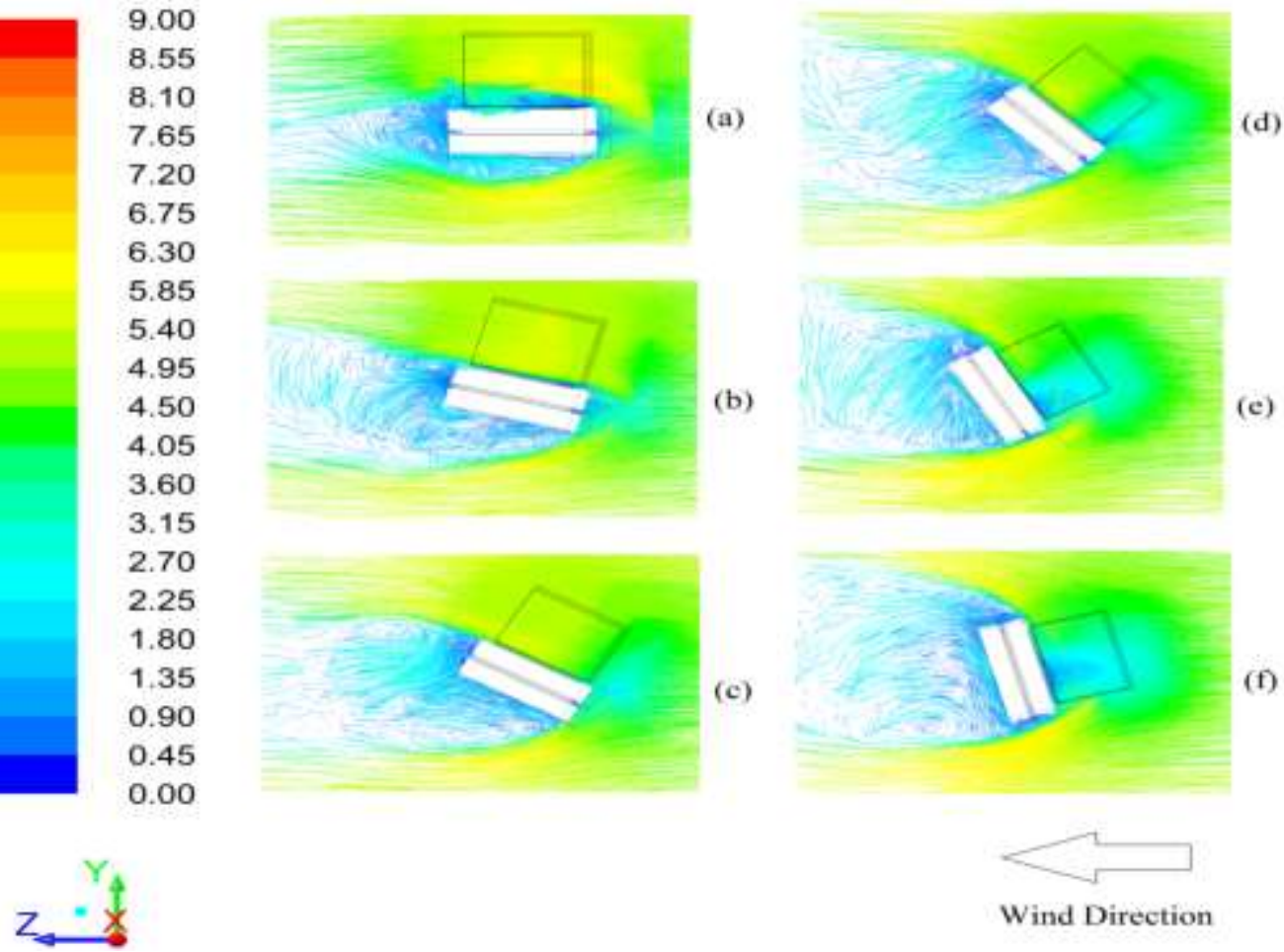

Wind Direction

Figure 14. Velocity vectors (Expanded and Cut-out) of the test assembly, (a) $0^{\circ}$ (b) $15^{\circ}$ (C) $30^{\circ}$ (d) $45^{\circ}$ (e) $60^{\circ}$ (f) $75^{\circ} \mathrm{AOA}$.

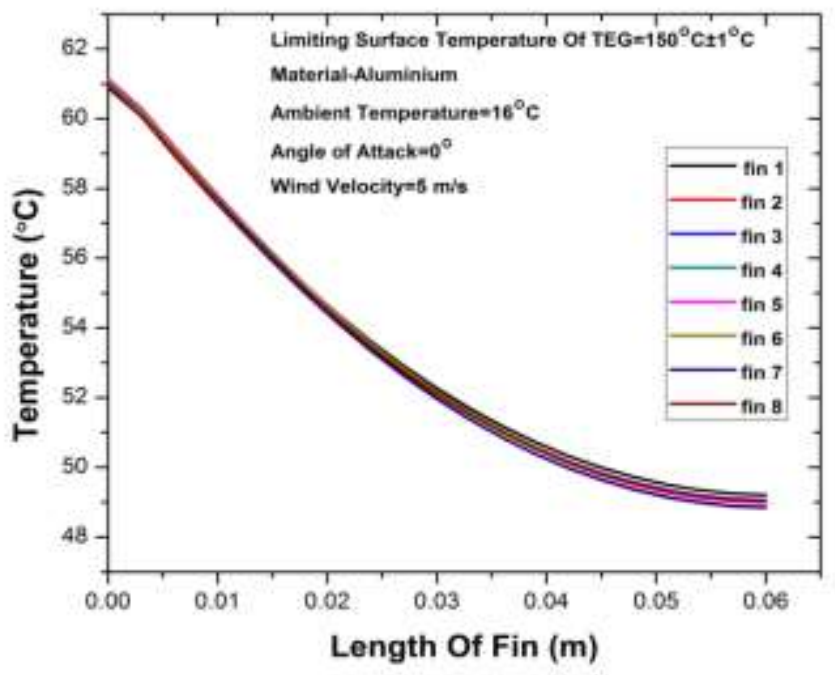

Figure 15.Variation of temperature $(\mathrm{K})$ with the length of fin for all 8 fins, for $0^{\circ} \mathrm{AOA}$. 


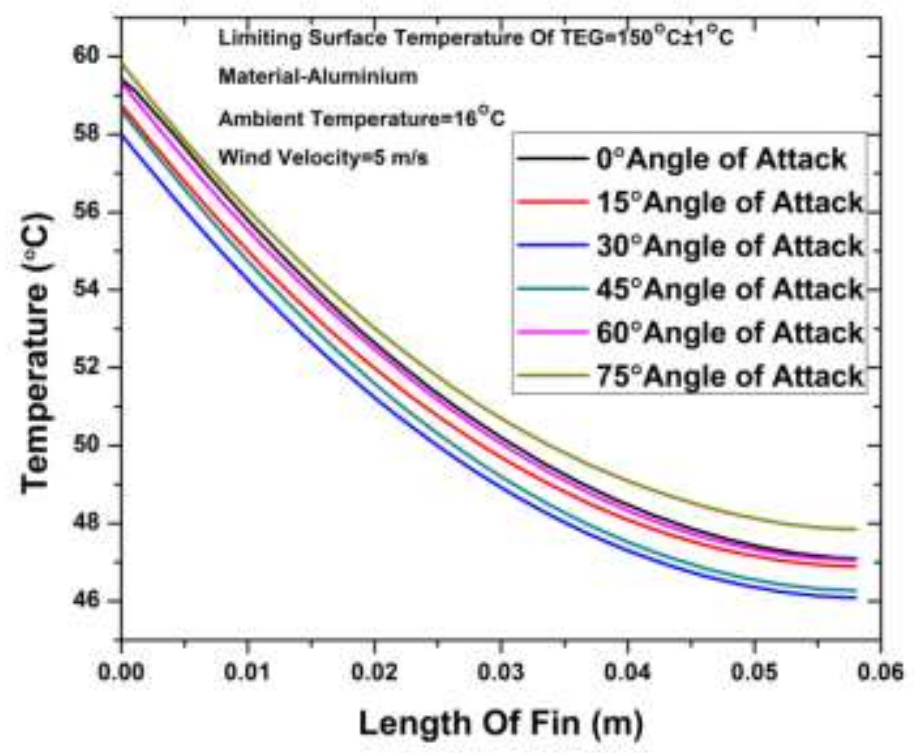

Figure 16.Variation of temperature $(\mathrm{K})$ with the length of the fin (Fin number1) for different AOA.

\section{Effect of Wind Direction}

Wind direction relative to fin face can attain any value depending upon the factors affecting the orientation of the test assembly like the latitude of the test location, 2 axis tracking of sun and local factors which affect the wind direction. For the current study, rather than changing the direction of wind at the wind tunnel inlet, the test apparatus has been rotated through 0 to 75 degrees in increments of 15 degrees to simulate the effect of wind direction on the limiting input heat flux on TEG as this approach is analogous to that of the wind flowing over the test assembly in different directions. The rotation has been carried out in only one direction keeping in mind symmetry about $\mathrm{X}-\mathrm{Z}$ plane, $\mathrm{Y}$ at $45 \mathrm{~mm}$. As can be seen from the figure. 17 the highest value of limiting heat flux occurs at $45^{\circ}$ rotation for all values of wind velocity.

$$
\mathrm{Nu} \text { ratio }=\frac{\mathrm{Nu}(\mathrm{X})}{\mathrm{Nu}(0 \text { degree })}
$$

$\mathrm{X}=0^{\circ}, 15^{\circ}, 30^{\circ}, 45^{\circ}, 60^{\circ}, 75^{\circ}$. 


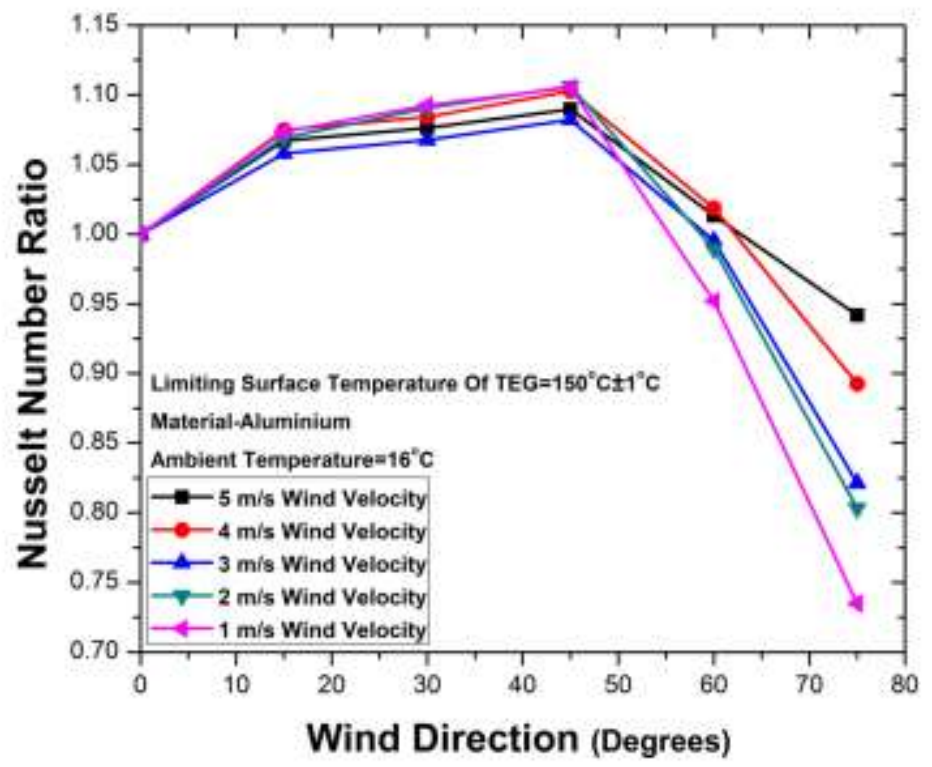

Figure 17.Variation of Nusselt number ratio with wind direction for different wind velocities.

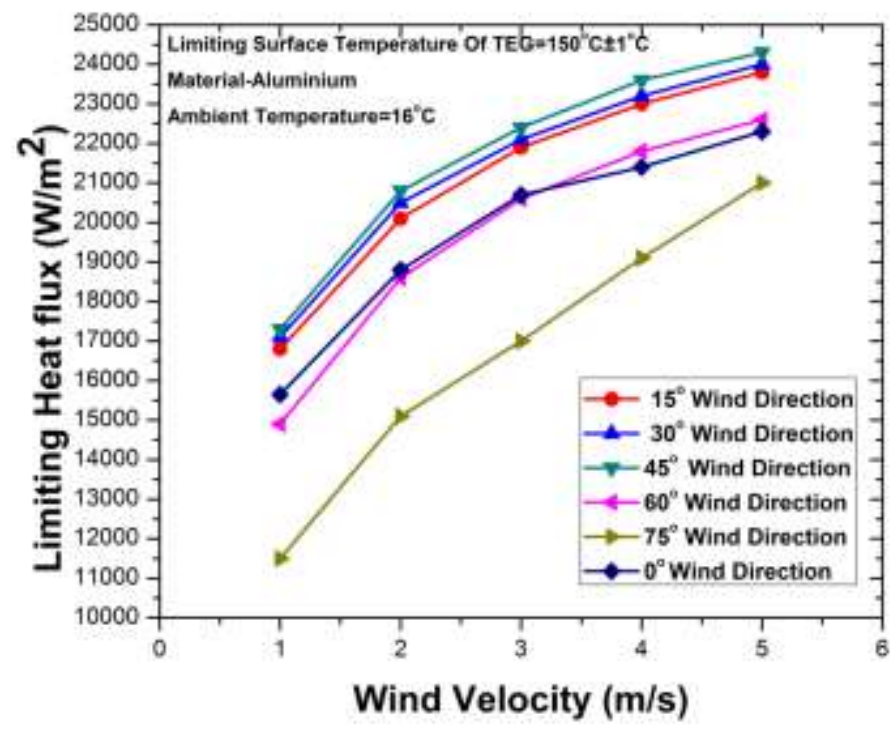

Figure 18. Variation of limiting input heat flux with wind velocity for different wind direction.

The Nusselt number ratio for different values of rotation under different wind has been presented in the figure. 18. As it can be seen the Nusselt number ratio rises with an increase in the degree of rotation up to $45^{\circ}$ where the peak is observed and then decreases sharply. This phenomena can be explained by the fact that the wind velocity is considerably lower than ambient (wind tunnel) within the fin spacing (Wind velocity increases with height), 
therefore the actual heat transfer coefficient adjacent to the fin face in the fin gap/spacing region is considerably lower than expected (co-relating with ambient wind velocity). But when the test block is rotated, the outer face of the windward side fin receives wind at velocities equal to ambient wind velocity thus enhancing the heat transfer. This coupled with the fact that with rotation the projected face area increases and the angular entry of wind into the fin spacing, breaks the thick boundary layer which is otherwise observed in the $0^{\circ}$ rotation case (figure. 21). When the angle of rotation is further increased, early separation of flow is observed from the leading edge. This hinders the entry of ambient air into the fin gaps thus hampering the heat transfer rate and lowering the limiting input heat flux. Figure. 19 represents the temperature contours of the domain for different wind directions. Fig. 20 represents the contours of the pressure and velocity for different values of rotation. As it can be seen pressure increases at the interface of fin edge and the base block with an increase in rotation angle. Stagnation point is observed at the point of intersection of the base block and fin edge. The wake region to increases with the degree of rotation, eddies, and recirculation for different rotation angles can be observed in the figure. 20.

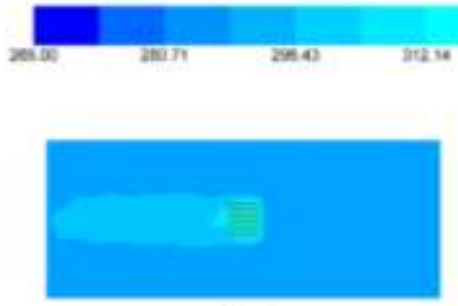

(a)

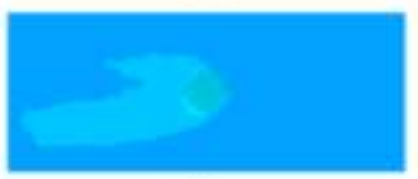

(d)

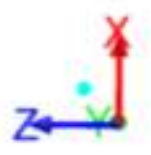

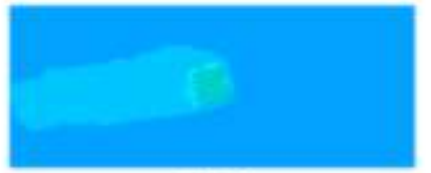

(b)

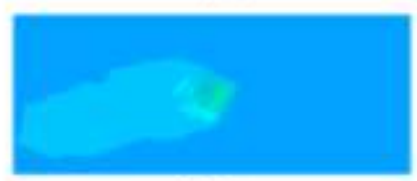

(e)

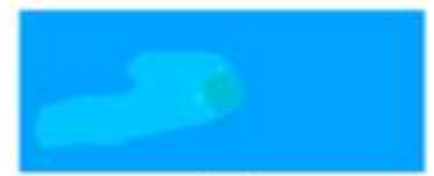

(c)

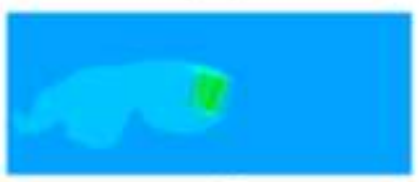

(f)

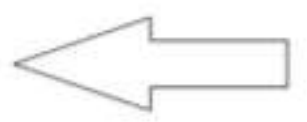

Wind Direction

Figure 19. The contour of temperature in the domain for (a) $0^{\circ}$ (b) $15^{\circ}$ (C) $30^{\circ}$ (d) $45^{\circ}$ (e) $60^{\circ}$ (f) $75^{\circ}$ Wind direction. 


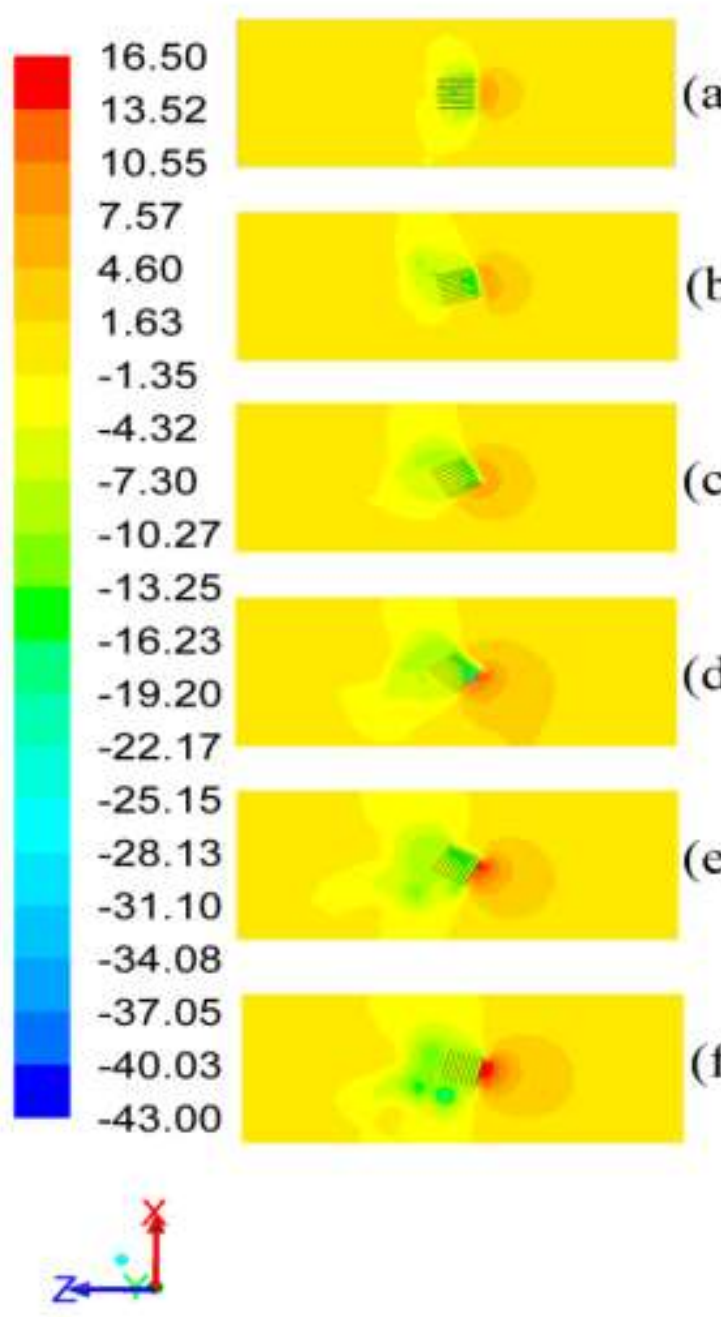

(a)

(b)

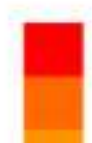

8.00

7.60

7.20

6.80

6.40

6.00

5.60

5.20

4.80

4.40

4.00

3.60

3.20

2.80

2.40

2.00

1.60

1.20

0.80

0.40

0.00

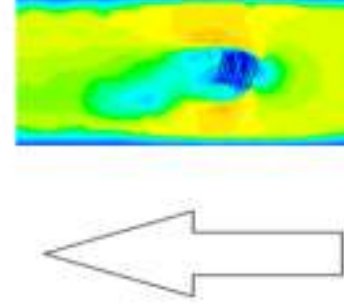

Wind Direction

Figure 20. Contours of pressure and velocity in the domain, pressure contours (a) $0^{\circ}$ (b) $15^{\circ}$ (C) $30^{\circ}$ (d) $45^{\circ}$ (e) $60^{\circ}$ (f) $75^{\circ}$ wind direction and velocity contours (g) $0^{\circ}$ (h) $15^{\circ}$ (i) $30^{\circ}$ (j) $45^{\circ}$ (k) $60^{\circ}$ (l) $75^{\circ}$ wind direction. 

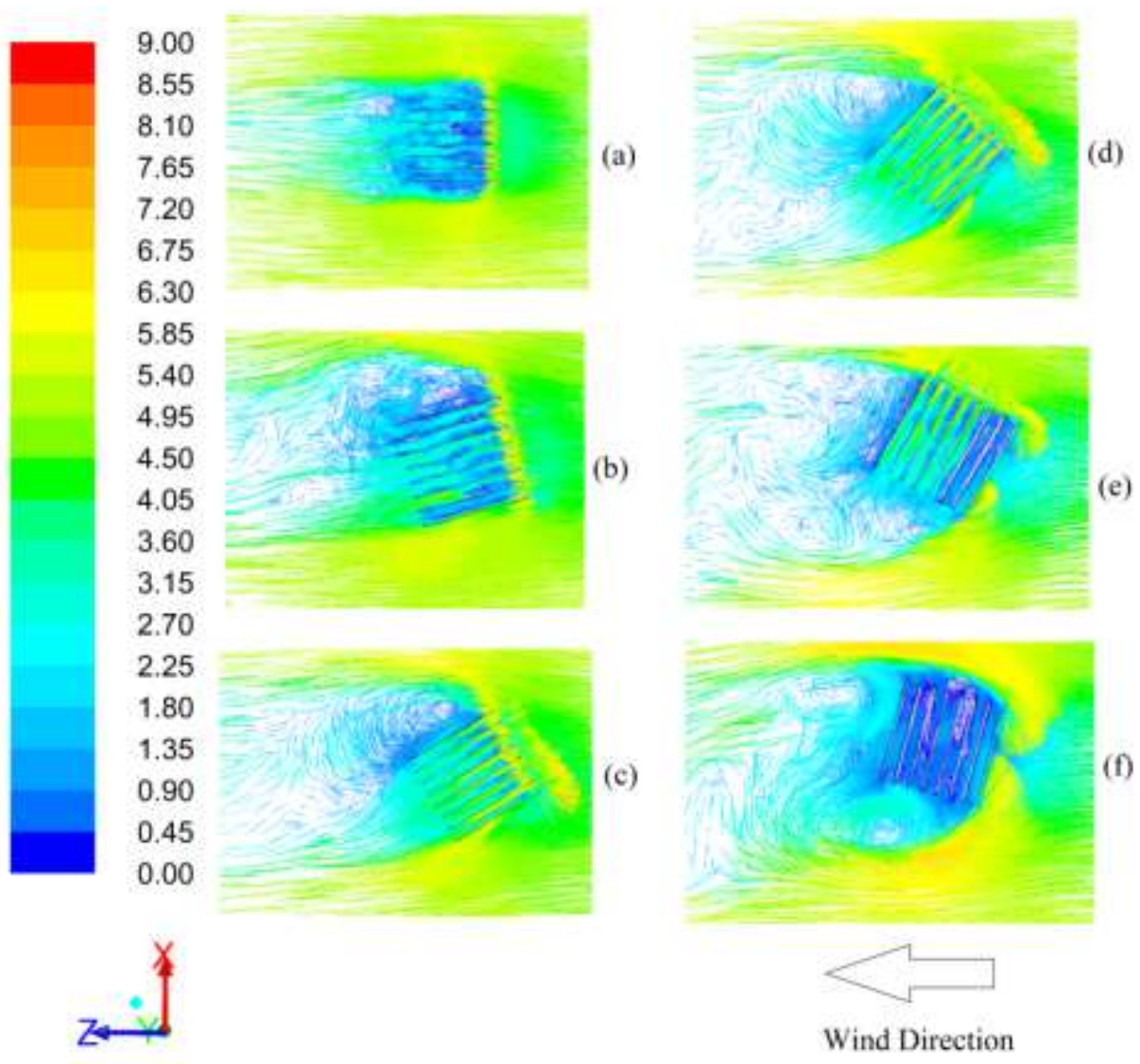

Figure 21.Velocity vectors (Expanded and Cut-out) of the test assembly, (a) $0^{\circ}$ (b) $15^{\circ}$ (C) $30^{\circ}$ (d) $45^{\circ}$ (e) $60^{\circ}$ (f) $75^{\circ}$ wind direction.

\section{CONCLUSIONS}

In this paper, the effect of various parameters namely, wind speed, ambient temperature, change of fin material from aluminum to copper and effect of Angle of Attack on the value of limiting input heat flux of TEG with limiting hot side temperature $150^{\circ} \mathrm{C}$ were analyzed. This research established that the increase in the input heat flux when the passive regime of wind velocity is changed to forced laminar would not justify the increase in the auxiliary power requirement of fan or blower employed to create higher wind velocities. Effect of angle of attack of the aluminum fin block on the limiting heat flux has been carried out and the effect of different angle of attack flowing over the fin block has been carried out and the material aspect of the fin block has been found out by this scientific research paper. This study also establishes that there is no advantage of using copper fin block over the aluminum finned block for heat dissipation. The temperature of copper and aluminum fin were determined for different heating elements producing different area aspect ratio. The study also delves into the concept of Angle of Attack and its effect on the limiting input heat flux as due to the tracking of sun the finned block makes a different angle with the oncoming wind direction during its diurnal operations. The effect of ambient temperature on the 
limiting input heat flux was also been investigated. This information will help in predicting the limiting input heat flux for TEG under concentrated solar flux operation with greater accuracy.

\section{ACKNOWLEDGMENTS}

I am very much thankful to all faculty members and students of GITAM.I also indebted to all teaching and non-teaching staff of the Department of Mechanical Engineering for their co-operation and suggestions regarding this scientific research paper.

\section{REFERENCES}

[1] Gurevich YG, Logvinov GN. Physics of thermoelectric cooling, Semicond. Sci. Technol. 2005; 20: R57-R64

[2] Baranowski LL, Snyder GJ, Toberer ES. Concentrated solar thermoelectric generators, Energy Environ. Sci. 2012; 5 (10): 9055-9067.

[3] Li P, Cai L, Zhai, P, Tang X, Zhang Q, Niino M, Design of a concentration solar thermoelectric generator. J. Electron. Mater.2010; 39 (9):1522-1530.

[4] Wang CC, Hung CI, Chen, WH. Design of heat sink for improving the performance of a thermoelectric generator using two stage optimization. Energy 2012; 39 (1): 236-245.

[5] Champier D, Bedecarrats JP, Rivaletto M, Strub F. 2010. Thermoelectric power generation from biomass cook stoves,Energy. 2010; 35 (2): 935-942.

[6] Champier D, Bedecarrats J.P, Kousksou T, Rigoletto, M., Strub, F., Pignolet, P., Study of a TE (thermoelectric) generator incorporated in a multifunction wood stove. 2011; Energy 36 (3): 1518-1526.

[7] Dresselhaus MS, Chen, G Tang, M Y Yang, R G, Lee H, Wang, D Z et al. New directions for low-dimensional thermoelectric materials, Adv. Mater. 2007; 19 (8) :1043-1053.

[8] Elghool A, Basrawi F, Ibrahim T K, Habib K, Ibrahim H, Idris DMND. A review on the heat sink for thermo-electric power generation: Classification and parameters affecting performance. Energy. Convers. Manage 2017; 134: 260-277.

[9] Singh R, Dundee S, Akbarzadeh A. Electric power generation from the solar pond using combined thermosyphon and thermoelectric modules. Sol. Energy 2011; 85 (2): 371-378.

[10] Fan H, Singh, RAkbarzadeh A. Electric power generation from thermoelectric cells using a solar dish concentrator. J. Electron. Mater.2011; 40 (5): 1311-1320.

[11] Date A, Dixon C, Singh R, Akbarzadeh A. Theoretical and experimental estimation of limiting heat flux for thermoelectric power generators with passive cooling. Sol. Energy 2015; 111: 201-217.

[12] Mahboub C, Moummi N, Moummi, A, Ali SY, Effect of the angle of attack on the wind convection coefficient. Sol. Energy 2011; 85: 776-780.

[13] Kendoush A A, Theoretical analysis of heat and mass transfer to fluids following across a flat plate. International Journal of Thermal Science 2009; 48: 188-194. 
[14] Turgut O, Onur N. Three dimensional numerical and experimental study on forced convection heat transfer on solar collector surface. International communications in Heat and Mass Transfer 2009;36: 274-279.

[15] Incropera F P. In: Hayton, J. (Ed.), Fundamentals of Heat and Mass Transfer, fifth ed. New York: John Wiley \& Sons; 2007

[16] Kwamsuk RK, Paornupatham P, Sathapornprasath K, Lertsatittanakorn C, Soponronnarit S. an experiment investigation on the performance of thermoelectric dehimidification system, Journal of Mechanical Engineering and Sciences 2018; 12(4):4117-4126.

[17] Muller E,Zabrocki K, Goupil C, Snyder GJ, Seifert W. Functionally graded thermoelectric generator and cooler elements.Taylor \& Francis; (1):36. 2012

[18] Baranowski LL, Jeffrey Snyder G, Toberer S E. Concentrated Solar Thermoelectric Generators. Energy Enviro. Sci. 2012; (5):9055.

[19] Kumar G, Sudhir KP. Efficiency Calculation of thermoelectric generator for investigating the applicability of various thermoelectric materials. Journal of renewable and sustainable energy 2017; (9):014701.

[20] Gurevich YG, Logvinov GN. Physics of thermoelectric cooling. Semicond. Sci. Technol. 2005; 20 (12): R57-R64. 